\title{
Added Value of Ultrasonography in Diagnosis of Rotator Cuff Injury
}

\author{
MOHSEN G. HASAN, M.D.; TAREK W. HEMEDA, M.D. and REHAB A.I. MOHAMMED, M.Sc. \\ The Department of Radio Diagnosis, Faculty of Medicine, Ain Shams University
}

\begin{abstract}
Background: Shoulder pain is one of the commonest musculoskeletal complaints presented to orthopedics and rheumatologists. Shoulder is a joint commonly affected by degenerative changes, overuse and traumatic lesions.

Aim of Study: The purpose of this study is to evaluate the role of dynamic high resolution ultrasonography in the detection of rotator cuff muscle injury, to find out the value added by dynamic ultrasonography to the static examination of such cases and to evaluate the value added by dynamic ultrasonographoy to the management of the disease. This is compared to MRI which we considered as a standard to our cases.
\end{abstract}

Material and Methods: This prospective study included 35 patients who were referred to the Radiology Department with clinically suspected rotator cuff injury. After detailed clinical examination, US examination of the involved shoulde was performed together with an examination of the contralateral normal shoulder, followed by MRI of the symptomatic shoulder in all 35 patients. The MRI findings were considered as final. Sensitivity and specificity for ultrasound in rotator cuff injuries was calculated with correlation with MRI.

Results: In the present study, the majority of patients were in age group 18-57 years. A total of 35 patients were diagnosed as having rotator cuff muscle abnormality on US and MRI. In the diagnosis of rotator cuff muscle tear, the strength of agreement between US and MRI was good.

Conclusion: Ultrasound of the shoulder show promising results in diagnosis of rotator cuff muscle injury and acromioclavicular join pathology. A wide viability, cost effectiveness and better tolerability of US make it amodality of first choice for evaluation in rotator cuff muscle pathology.

Key Words: Ultrasonography - Rotator cuff injury - Shoulder pain.

\section{Introduction}

SHOULDER pain is the third most common cause of joint pain after low back pain and knee pain.

Correspondence to: Dr. Mohsen G. Hasan, The Department of Radio Diagnosis, Faculty of Medicine, Ain Shams University
Rotator cuff injury is the most common cause, present in approximately $85 \%$ of the cases. Rotator cuff injuries range from simple inflammations to complete tears [1].

Shoulder injuries are common accounting for up to $20 \%$ of all athletic injuries. The unique structure of the shoulder joints results in a multiaxial universal joint with an unparalleled range of motion. However, this unique structure also means that the shoulder joint is the most frequently dislocated joint in the body. In addition to shoulder dislocations, other common injuries include rotator cuff tendon pathologies and broken bones including the humerus and collar bone [2]

The role of imaging is to guide treatment decision. The diagnosis of rotator cuff injury, tendinopathy or partial or full thickness tear, and its extent can determine whether the patient will undergo surgery or just will be managed conservativel. Also the surgical approach, open versus arthroscopic, is chosen based on the imaging diagnosis. MRI is now widely used and considered to be a reliable technique for the evaluation of the different causes of shoulder pain with the advantages of providing excellent soft tissue details, tendon retraction and extension of the tear to adjacent structures MRI. However, has certain disadvantages like being expensive, providing a static evaluation, not readily available, difficult to interpret when adjacent metallic implant is present due to artifacts and has many contraindications like claustrophobia etc [3].

Dynamic ultrasonography is a useful tool for the evaluation of a wide variety of musculoskeletal disorders that are best or only shown dynamically that is, during motion, muscle contraction, probe 
compression, or position change of the patient. Many of these disorders cannot be diagnosed by any other imaging method with the advantage of being readily available, relatively inexpensive and non-invasive. However, having the disadvantages of being operator dependent, requiring standardized scanning technique and in comparison to MRI, it is constantly reported to have a lower sensitivity and specificity for detection of rotator cuff tears [4].

Many studies have been conducted to determine the accuracy of ultrasound in the detection of rotator cuff tears which proved to be of high accuracy in detection of full thickness tears but of relatively low accuracy in detection of partial thickness tear [5].

Other studies were conducted to compare the accuracy of ultrasound and unenhanced MRI in the detection and follow-up of rotator cuff tears. However, there is a need for more studies to determine the accuracy of ultrasound in detection of probable associated image findings, its accuracy in diagnosis of tendinopathy and conclude possible criteria of patients in whom investigation by ultrasound could be addressed as the first line of investigation [6].

US is an established and well-accepted modality for the evaluation of articular and peri-articular structures around the shoulder. It is useful in wide range of rotator cuff diseases, non-rotator cuff abnormalities (instability problems, synovial joint diseases, and nerve entrapment syndromes). High resolution Ultrasonography can be regarded as effective primary modalities of imaging for most of the shoulder pathologies to expedite patient care $\left[{ }^{7}\right]$.

\section{Aim of the work:}

The purpose of this study is to evaluate the role of dynamic high resolution ultrasonography in the detection of rotator cuff muscle injury, to find out the value added by dynamic ultrasonography to the static examination of such cases and to evaluate the value added by dynamic ultrasonographoy to the management of the disease. This is compared to MRI which we considered as a standard to our cases.

In the developing countries, the cost/ effectiveness is a very important issue in the evaluation of any diagnostic examination, so we have a goal to offer an accurate and highly sensitive diagnostic method for the cases of painful shoulder, being widely spread and of low cost.

\section{Patients and Methods}

This prospective study was conducted on patients referred from the orthopedic clinic to Ultrasound Unit at Ain Shams University Hospitals for US examination of shoulder joint followed by MRI of the symptomatic shoulder in all patients.

About 35 patients were included (10 females $\& 15$ males) and their age ranged from 18 to 57 years with mean age $34.17 \pm 12.36$ years. This study was carried out from January 2019 to July 2019.

The patients who were clinically suspected of rotator cuff injuries were included in the study. While, patients with contraindications to MRI, those with known or diagnosed fracture/dislocation involving the shoulder on plain radiography and who had undergone shoulder surgery for any reason were excluded from the study.

\section{Inclusion criteria:}

- History of pain in either of the shoulder.

- History of restricted movements in either shoulder.

- Clinically suspected to have internal derangements like rotator cuff injury, biceps tendon injury, calcific tendinitis

Exclusion criteria:

- Patients with glenoid labral pathologies.

- Patients with instability disorders.

- Patients with any electrically, magnetically or mechanically activated implants (pacemaker, biostimulators, neurostimulators and cochlear implants).

- Patients having claustrophobia.

Written consents were taken from the patients according to ethical committee considerations.

\section{MRI technique:}

The study was performed on super conductive MRI scanner (Philips Achieva-XR 1.5 Tesla) using standard scanning protocol:

- All metallic objects should be removed from the patient's body.

- Patient position: The patient is positioned supine on MRI table. 
- Patient will be instructed about the importance of being calm with no motion throughout time of examination.

- Shoulder protocol:

- Axial scout.

- Axial T1, gradient.

- Coronal oblique T1, PD, T2.

- Sagital oblique T1, T2.

\section{Ultrasound technique:}

US evaluation of the shoulder is primarily performed with the patient is sitting on the table. it is preferred to scan while standing behind the patient. The probe should be held at its end with the edge of the hand resting on the shoulder of tha patient in order to reduce stress and allow fine motor control.

Scanning is performed with a high-frequency (ideally, $12 \mathrm{MHz}$ ) linear transducer, although a lower frequency $(7-9 \mathrm{MHz})$ transducer is sometimes better suited for evaluating the deep structures.

\section{Statistical analysis:}

Data were collected, revised, coded and entered to the Statistical Package for Social Science (IBM SPSS) version 23. The quantitative data were presented as mean, standard deviations and ranges when parametric. Also qualitative variables were presented as number and percentages. So, the $p$ value was considered significant as the following: $p$-value $>0.05$ : Non Significant (NS), $p$-value <0.05: Significant $(\mathrm{S}), p$-value $<0.01$ : Highly Significant (HS).

\section{Results}

Table (1): Relation between results of rotator cuff muscle tendinopathy by US and MR.

\begin{tabular}{|c|c|c|c|c|c|c|}
\hline & \multicolumn{4}{|c|}{ Tendinopathy MRI } & \multirow{3}{*}{$\begin{array}{c}\text { Test } \\
\text { value* }\end{array}$} & \multirow{3}{*}{$\underset{\text { value }}{p-}$ Sig } \\
\hline & \multicolumn{2}{|c|}{ Negative } & \multicolumn{2}{|c|}{ Positive } & & \\
\hline & No. & $\%$ & No. & $\%$ & & \\
\hline \multicolumn{7}{|c|}{ Tendinopathy US: } \\
\hline Negative & 29 & 100.0 & 2 & 33.3 & 21.828 & $0.000 \mathrm{HS}$ \\
\hline Positive & 0 & 0.0 & 4 & 66.7 & & \\
\hline
\end{tabular}

$p$-value $>0.05$ : Non Significant (NS).

$p$-value $<0.05$ : Significant $(\mathrm{S})$.

$p$-value $<0.01$ : Highly Significant (HS)

*: Chi-square test.

Table (1) shows that there was highly statistically significant relation found between MRI \& US regarding rotator cuff muscle tendinopathy.
Table (2): Relation between results of partial thickness (bursal) by US and MR.

\begin{tabular}{|c|c|c|c|c|c|c|}
\hline & & $\begin{array}{l}\text { artial t } \\
\text { (bursa }\end{array}$ & $\begin{array}{l}\text { hickı } \\
\text { l) } \mathrm{Ml}\end{array}$ & $\begin{array}{l}\text { ness } \\
\text { RI }\end{array}$ & \multirow{3}{*}{$\begin{array}{c}\text { Test } \\
\text { value* }\end{array}$} & \multirow{3}{*}{$\underset{\text { value }}{p-}$ Sig. } \\
\hline & \multicolumn{4}{|c|}{ Negative Positive } & & \\
\hline & No. & $\% \mathrm{I}$ & No. & $\%$ & & \\
\hline \multirow{2}{*}{\multicolumn{7}{|c|}{$\begin{array}{l}\text { Partial thickness } \\
\text { (bursal) US: }\end{array}$}} \\
\hline & & & & & & \\
\hline \multirow{2}{*}{$\begin{array}{l}\text { Negative } \\
\text { Positive }\end{array}$} & 32 & 94.1 & 0 & 0.0 & 10.980 & $0.001 \mathrm{HS}$ \\
\hline & 2 & 5.9 & 1 & 100.0 & & \\
\hline
\end{tabular}

Table (2) shows that there was highly statistically significant relation found between MRI \& US regarding partial thickness (bursal).

Table (3): Relation between results of partial thickness (articular) by US and MR.

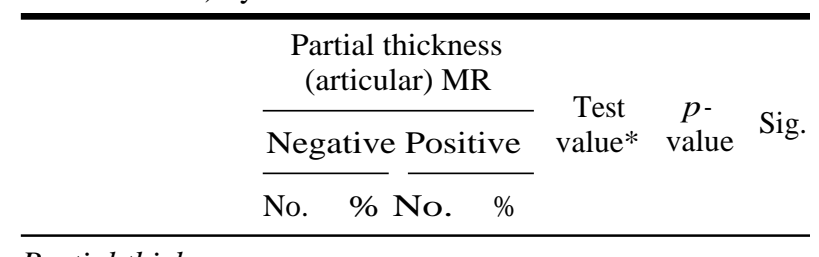

Partial thickness

(articular) US:

\begin{tabular}{lllllll} 
Negative & 22 & 91.7 & 4 & 36.4 & 12.077 & $0.001 \mathrm{HS}$ \\
Positive & 2 & 8.3 & 7 & 63.6 & & \\
\hline
\end{tabular}

$p$-value $>0.05$ : Non Significant (NS).

$p$-value $<0.05$ : Significant $(\mathrm{S})$

$p$-value $<0.01$ : Highly Significant (HS)

$*$ : Chi-square test.

Table (3) shows that there was highly statistically significant relation found between MRI \& US regarding partial thickness (articular).

Table (4): Relation between results of partial thickness (interstitial) by US and MR.

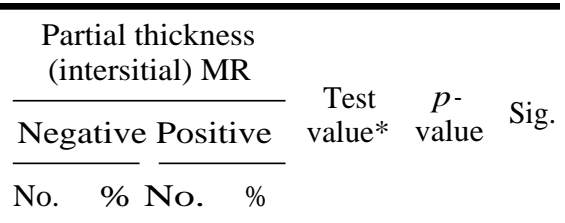

\begin{tabular}{llllllll}
\hline $\begin{array}{l}\text { Partial thickness } \\
\text { (interstitial) US: }\end{array}$ & & & & & & \\
Negative & 31 & 96.9 & 2 & 66.7 & 4.646 & 0.031 & $\mathbf{S}$ \\
Positive & 1 & 3.1 & 1 & 33.3 & & & \\
\hline$p$-value $>0.05$ : Non Significant (NS). & & & \\
$p$-value <0.05: Significant (S). \\
$p$-value <0.01: Highly Significant (HS). \\
$*$ : Chi-square test.
\end{tabular}


Table (4) shows that there was highly statistically significant relation found between MRI \& US regarding partial thickness (interstitial).

Table (5): Relation between results of full thickness (incomplete) by US and MR.

\begin{tabular}{|c|c|c|c|c|c|c|}
\hline & & $\begin{array}{l}\text { Full th } \\
\text { comp }\end{array}$ & $\begin{array}{l}\text { ckne } \\
\text { ete) }\end{array}$ & $\begin{array}{l}\text { SS } \\
\text { MR }\end{array}$ & & \\
\hline & $\mathrm{Neg}$ & rative & Pos & itive & value* & value Sig. \\
\hline & No. & $\%$ & No. & $\%$ & & \\
\hline $\begin{array}{l}\text { Full thickne } \\
\text { (incomplete }\end{array}$ & & & & & & \\
\hline Negative & 27 & 96.4 & 3 & 42.9 & 13.125 & $0.000 \mathrm{HS}$ \\
\hline Positive & 1 & 3.6 & 4 & 57.1 & & \\
\hline
\end{tabular}

Table (5) shows that there was highly statistically significant relation found between MRI \& US regarding full thickness (incomplete).

Table (6): Relation between results of full thickness (complete) by US and MR.

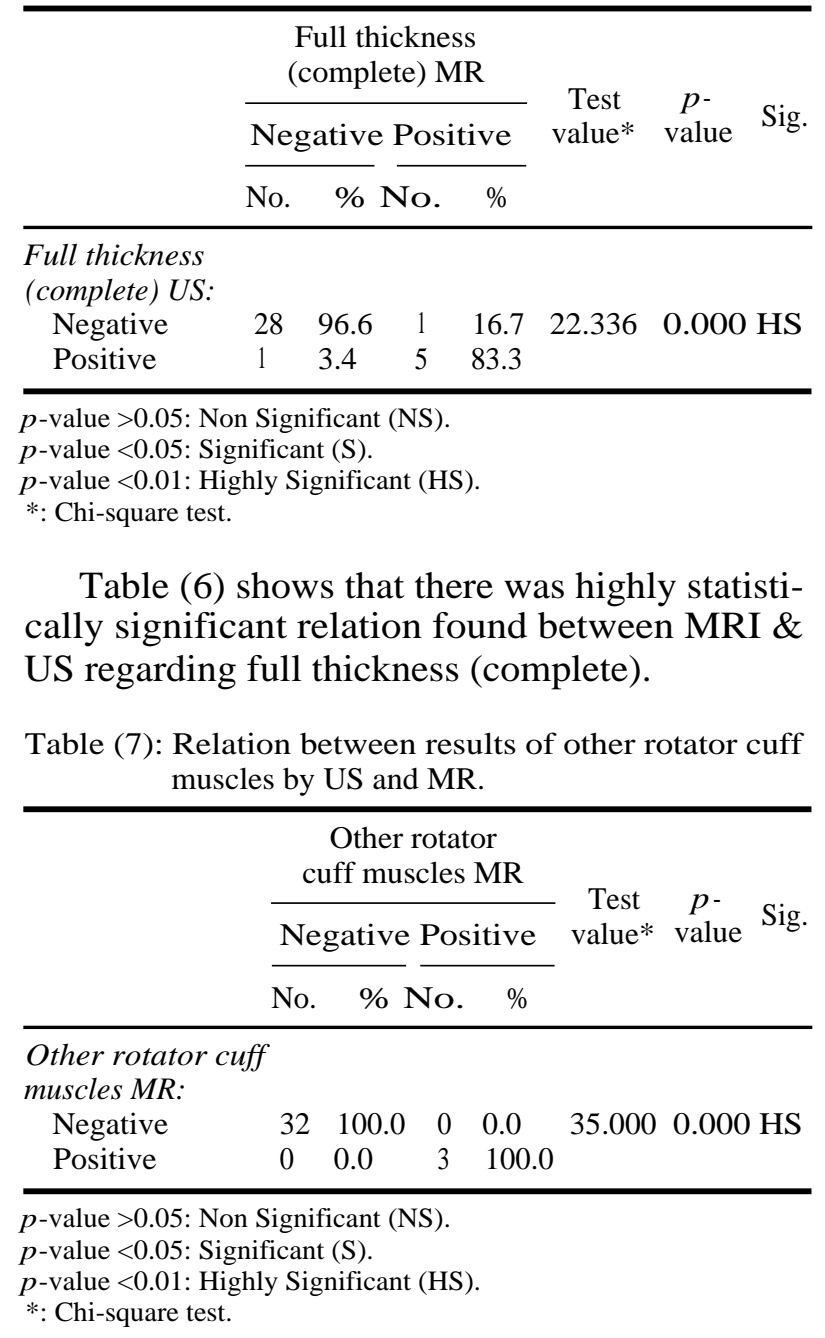

Table (7) shows that there was highly statistically significant relation found between MRI \& US regarding other rotator cuff muscles.

Table (8): Relation between results of ACJ disease by US and MR.

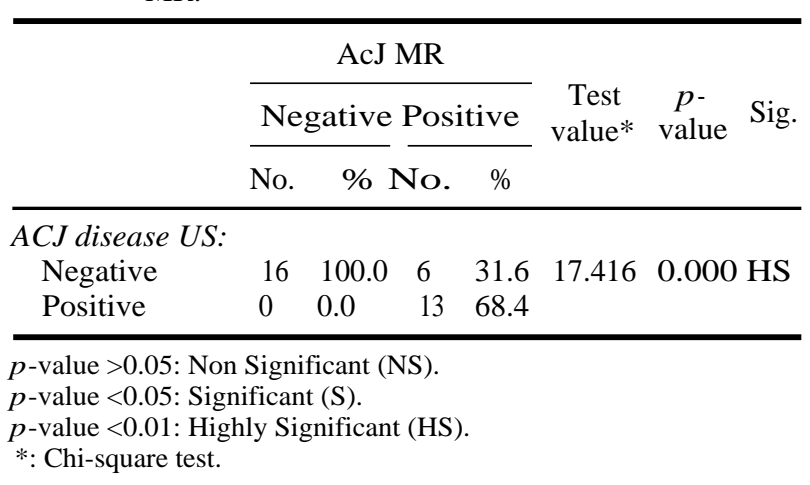

Table (8) shows that there was highly statistically significant relation found between MRI \& US regarding ACJ disease.

Table (9): Relation between results of bursal by US and MR.

\begin{tabular}{|c|c|c|c|c|c|c|}
\hline & \multicolumn{4}{|c|}{ Bursa MR } & \multirow{3}{*}{$\begin{array}{c}\text { Test } \\
\text { value* }\end{array}$} & \multirow{3}{*}{$\begin{array}{c}p- \\
\text { value }\end{array}$} \\
\hline & \multicolumn{2}{|c|}{ Negative } & \multicolumn{2}{|c|}{ Positive } & & \\
\hline & No. & $\%$ & No. & $\%$ & & \\
\hline \multicolumn{7}{|l|}{ Bursal US: } \\
\hline Negative & 29 & 100.0 & 1 & 16.7 & 28.194 & $0.000 \mathrm{HS}$ \\
\hline Positive & 0 & 0.0 & 5 & 83.3 & & \\
\hline
\end{tabular}

Table (9) shows that there was highly statistically significant relation found between MRI \& US regarding bursal disease.

Table (10): Relation between results of total by US and MR.

\begin{tabular}{|c|c|c|c|c|c|c|}
\hline & \multicolumn{4}{|c|}{ Total MRI } & \multirow{3}{*}{$\begin{array}{c}\text { Test } \\
\text { value* }\end{array}$} & \multirow{3}{*}{$\begin{array}{c}p- \\
\text { value }\end{array}$} \\
\hline & \multicolumn{2}{|c|}{ Negative } & \multicolumn{2}{|c|}{ Positive } & & \\
\hline & No. & $\%$ & No. & $\%$ & & \\
\hline \multicolumn{7}{|l|}{ Bursal US: } \\
\hline Negative & 246 & 97.2 & 19 & 30.6 & 165.348 & $0.000 \mathrm{HS}$ \\
\hline Positive & 7 & 2.8 & 43 & 69.4 & & \\
\hline
\end{tabular}

Table (10) shows that there was highly statistically significant relation found between MRI \& US regarding total. 


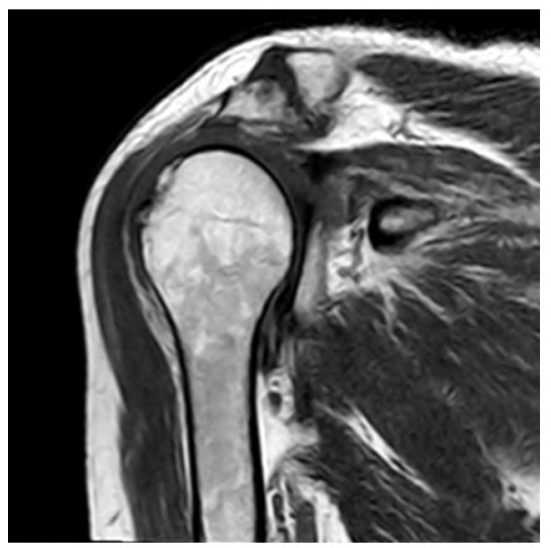

(A)

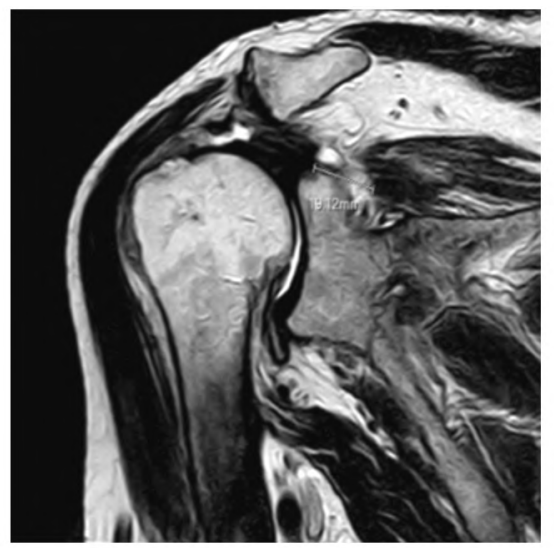

(B)

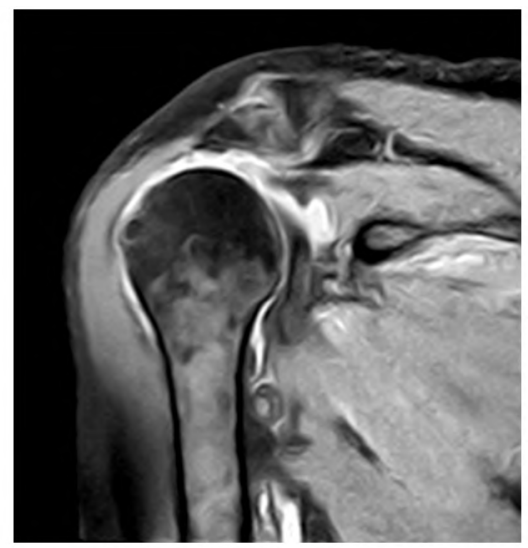

(C)

Fig. (1): (A) Coranal T1W image show osteophtic lipping of articular surface denoting AC osteoarthritis, (B) Coronal T2W show focal gapping $(19 \mathrm{~mm})$ of supraspinatous muscle denoting full thickness tear, (C) Coronal PD SPIR fluid signal within joint denoting glenohumeral joint effusion.

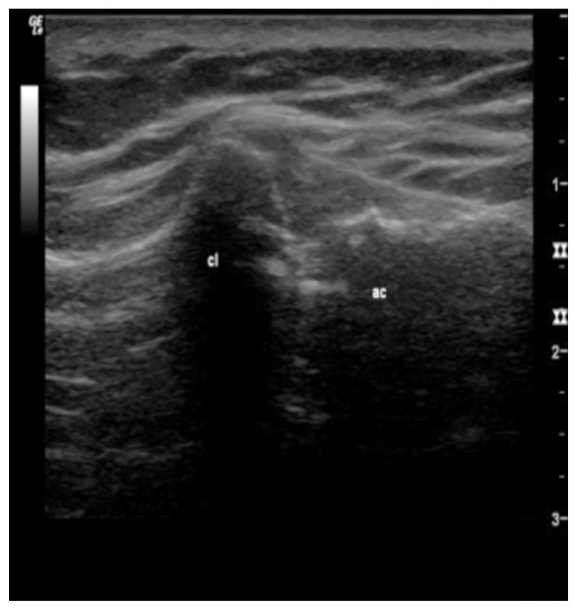

(D)

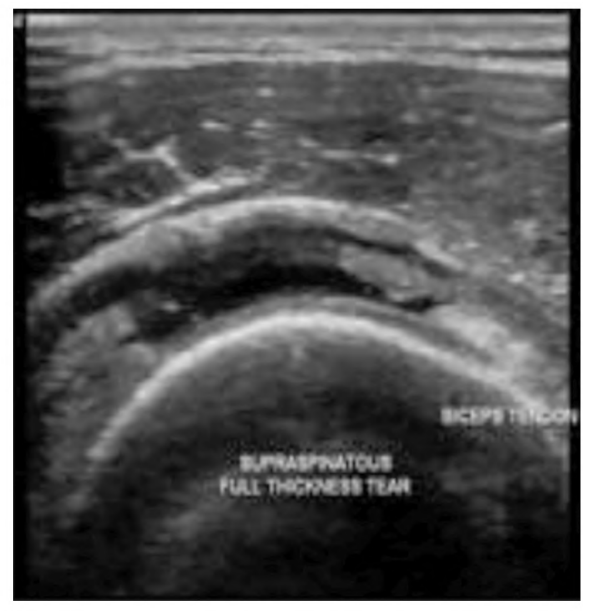

(E)

Fig. (1): (D) US show AC osteoarthritic changes, (E) Show hypoechoic gapping within all muscle thickness denoting full thickness tear.

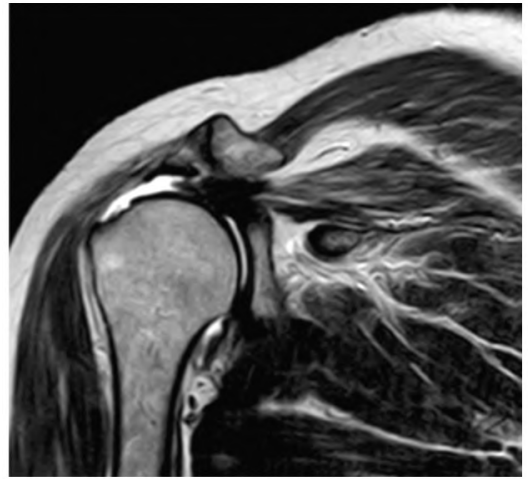

(A)

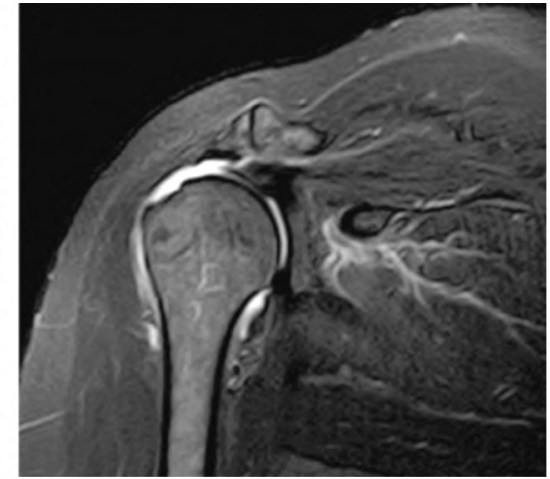

(B)

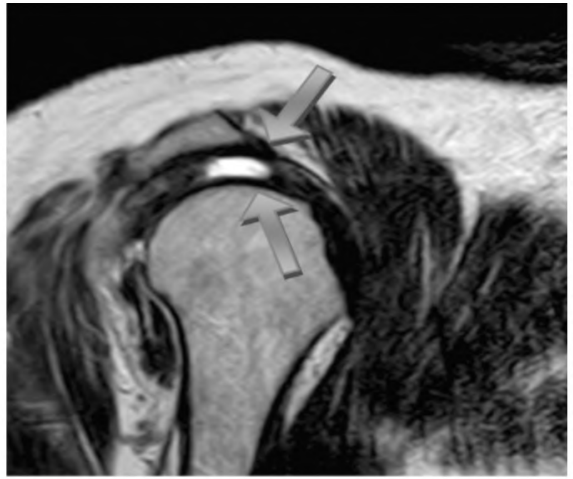

(C)

Fig. (2): (A, B) MRI, coronal T2 WI showing osteo-arthritic changes of acromio-clavicular joint and marked thinning of the supraspinatou ms mounting to full thickness tear with fluid signal is noted at its region associated with severe atrophic changes of muscle belly, (C) T2 sagital oblique show anterior hook configuration of acomion. 


\section{Ultrasound images:}

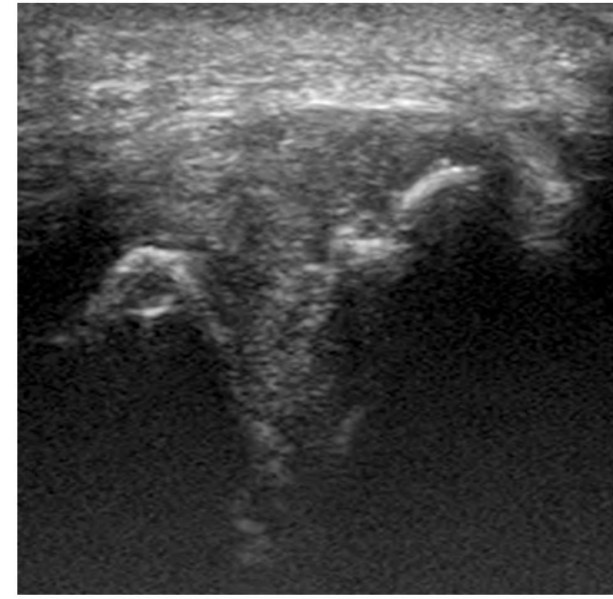

(D)

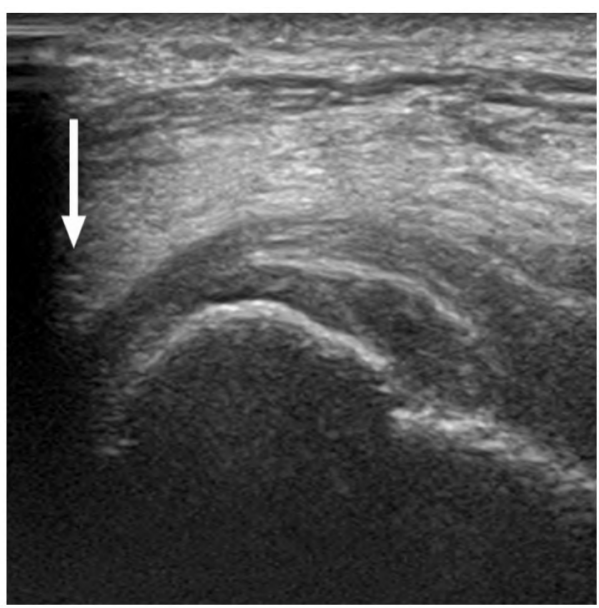

(E)

Fig. (2): (D) US images shows evidence of acromio-clavicular osteoarthritis. (E) US shows marked thinning mounting to complete torn supraspinatous tendon (white arrow).

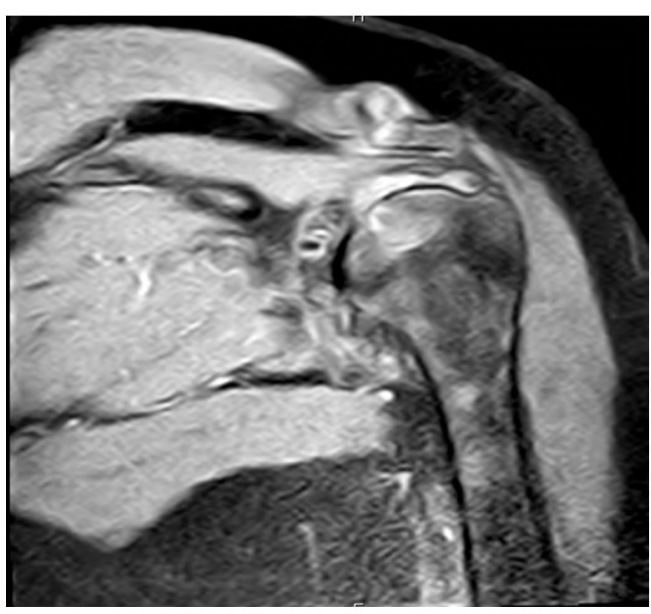

(A)

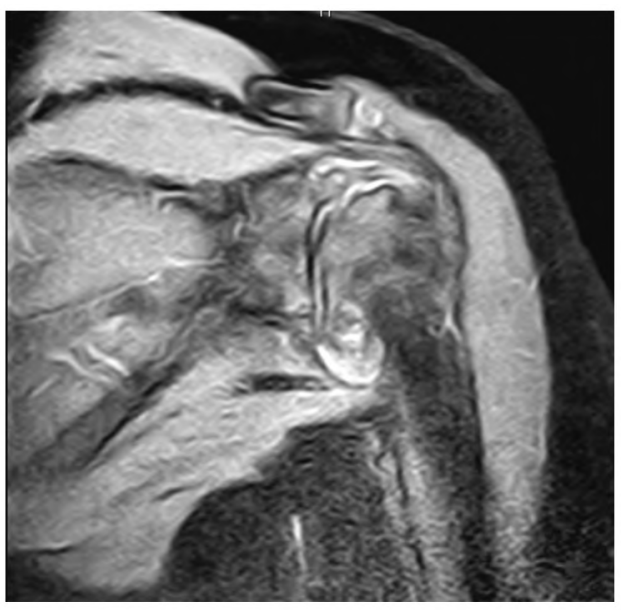

(B)

Fig. (3): (A) Coronal PD SPIR image show abnormal signal of tendon near its attachment denoting partial thickness tear (articular), (B) Coronal PD image show abnormal fluid signal within glenohumeral joint denoting effusion.

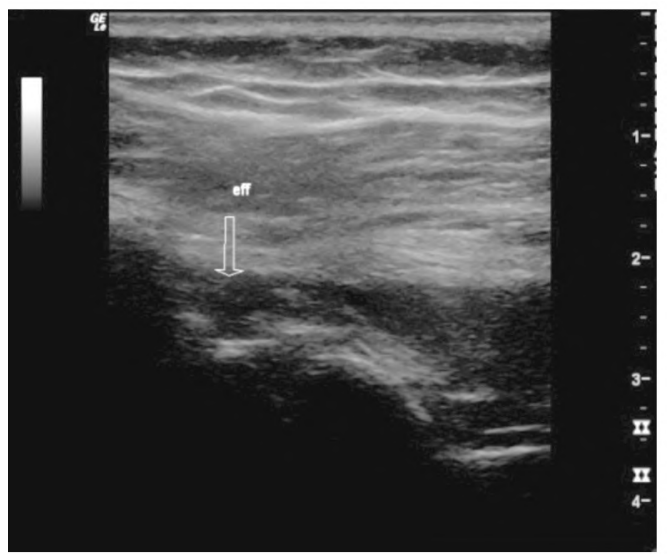

(C)

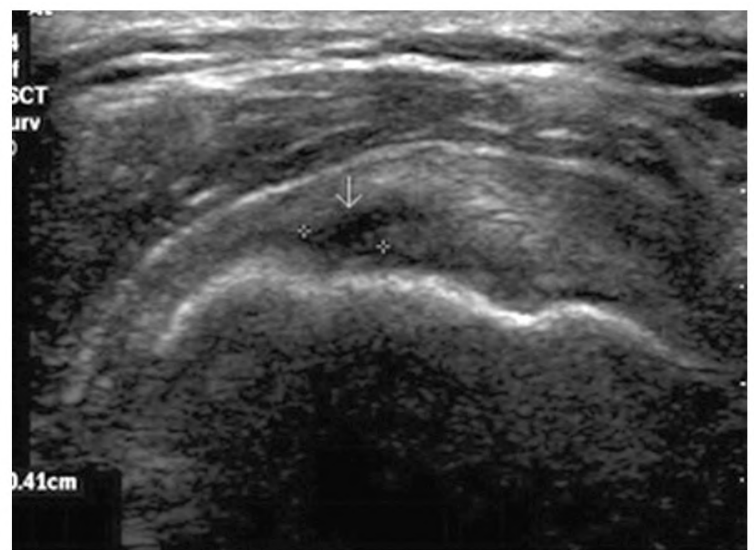

(D)

Fig. (3): (C) US show hypoechogenicity within glenohumeral joint denoting effusion. (D) US show hypoechogenicity of supraspinatus tendon near its attachment denoting partial thickness tear (articular). 


\section{Discussion}

The purpose of this study is to evaluate the role of dynamic high resolution ultrasonography in the detection of different abnormalities of shoulder joint, to find out the value added by dynamic ultrasonography to the static examination of such cases and to evaluate the value added by dynamic ultrasonography to the management of the disease. This is compared to MRI which we considered as a standard to our cases.

In the developing countries, the cost/ effectiveness is a very important issue in the evaluation of any diagnostic examination, so we have a goal to offer an accurate and highly sensitive diagnostic method for the cases of painful shoulder, being widely spread and of low cost.

Our study included 35 patients referred to Radio-Diagnosis Department at Ain Shams University Hospitals.

The age of patients ranged from 18 to 57 years old with mean age $34.17 \pm 12.36$ years.

Our results show agreement with another study of Bashir et al., [8], to evaluate and compare ultrasonography to MRI in diagnosis of rotator cuff pathologies and tear, with a sensitivity of $88.89 \%$ and specificity of $100 \%$, in comparison to our study which revealed 83.3 sensitivity and $96.6 \%$ specificity for full thickness tear. In comparing the results for partial thickness tears (articular), Bashir et al., [8], showed sensitivity of $78.04 \%$, specificity of $89.47 \%$, while our study showed sensitivity $63.3 \%$ and specificity $91.7 \%$. In comparing the results for partial thickness tears (intersitial), Bashir et al., [8], showed sensitivity of $80.04 \%$, specificity of $89.47 \%$, while our study showed sensitivity $33.3 \%$ and specificity $96.9 \%$.

Our results also are comparable and coincide with the study of Chauhan et al., [6], it shows sensitivity of $86.7 \%$ and a specificity of $100 \%$ for full-thickness tear, sensitivity of $89.7 \%$ and a specificity of $98.8 \%$ for partial-thickness tear.

Subacromial subdeltoid bursitis was identified in 6 cases by MRI, 1 of them weren't seen by ultrasound.

Results as regard the previous findings are compared with many studies and revealed:

Our results are in agreement with Bruyn et al., [9] study that compare ultrasound and MRI assessment of subdeltoid/subacromial bursitis, with sensitivity of $83.3 \%$ and specificity of $100 \%$.
Acromioclavicular joint pathologies (osteoarthritic changes):

In our study, acromioclavicular joint osteoarthritic changes were diagnosed by MRI in 19 cases, with 13 cases diagnosed by ultrasound. Narrowing of joint space, hypertrophy of the capsule, irregular articular margins and osteophytic hypertrophy was noted in the diagnosed cases.

The previous results show comparable agreement with Sanverdi et al., [10] study in assessment of sonographic ability in detecting mild and early degree of acromioclavicular osteoarthritic changes. Study states that ultrasound is reliable in detecting early osteoarthritic changes of acromioclavicular joint, with $68.4 \%$ sensitivity and $100 \%$ specificity.

\section{- Other rotator cuff injuries:}

In our study, MRI diagnosed 3 cases of infraspinatous and subscapularis injury, the 3 cases are diagnosed by ultrasound.

Comparing the previous finding results with Bruyn et al., [11] study results, our results show sensitivity of $100 \%$ and specificity of $100 \%$ which is almost comparable with Bryun et al., [11] study which shows sensitivity (85.7\%) and specificity (98.3\%).

\section{- Studies and articles review:}

De Jesus et al., [12] cited that ultrasound is as accurate as MRI for both rotator cuff full-thickness tears and partial thickness tears while MR arthrography is more accurate than MRI and ultrasound in diagnosing rotator cuff tears. These results, combined with the lower cost for ultrasound, suggest that ultrasound may be the most cost-effective imaging method for screening for rotator cuff tears provided that the examiner has been properly trained in this operator-dependent technique. MR arthrography can be performed in cases in which ultrasound and MRI are not definitive.

Levine et al., [13] in the review about comparison between ultrasound and MRI in shoulder imaging, declared that both MRI and ultrasound are well suited for the evaluation of shoulder pain and should be considered complementary imaging modalities. MRI is indicated when there is question of an abnormality related to the labrum, articular cartilage, bone marrow, or deep soft tissues. Ultrasound has advantages over MRI when imaging around hardware, for detecting foreign bodies, when there is need to perform a dynamic maneuver to elicit pathology, and for guiding procedures. Ultrasound is indicated also if the patient has a pacemaker, has a non-MRI-compatible metal im- 
plant, or is claustrophobic. Ultrasound and MRI have shown similar diagnostic efficacies for evaluation of the rotator cuff. Ultrasound has higher value in evaluation of a focal tendon abnormality (rotator cuff or biceps), soft tissue fluid collection, or confirmation of a benign cyst (ganglion cyst).

Several meta-analyses was done, Smith et al., [2] and Roy et al., [14]; the last was about diagnostic accuracy of ultrasonography, MRI and MR arthrography in the characterization of rotator cuff disorders, with analysis of 82 articles, results indicate an equivalent performance of the three imaging modalities (US, MRI and MRA) in the diagnosis of full or partial rotator cuff tears.

In the other analyses by Smith et al., [2] similar results as those found in Roy et al., [14] study were obtained; however, for partial thickness RC tears for US, differences were noted, with slightly higher accuracy of ultrasound. This could be explained by the fact that some studies that were included in the last review were excluded in the first one for several reasons like study population ineligible, not in English, surgery not the reference standard. The studies confirm the similar and high diagnostic accuracy of Ultrasonography (US) as MRI, with slightly higher accuracy of MR Arthrography (MRA) in the characterisation of Rotator Cuff (RC) tears in individuals with shoulder pain.

\section{- Current study recommendation:}

Our study recommendation coincides with the fore mentioned articles, and reviews: High resolution ultrasonography diagnostic ability in different shoulder pathologies shows nearly perfect agreement with MRI results for assessment of muscular pathologies (rotator cuff tears and tendinopathy, long head of biceps tenosynovitis), Joint effusion, synovitis, osteoarthritic changes. Ultrasonography still has limited role in evaluation of deeply seated structures (glenoid labrum, deep articular cartilage), with inability to assess bone marrow lesions.

Ultrasound shows many advantages over MRI in easiness of the procedure for the patient, more cost reduction, less time consuming, and available for the patient with contraindications for MRI (Pace maker, cochlear implant, claustrophobia). Also ability of dynamic assessment of affected tendon and muscle, Doppler evaluation of various lesions, higher resolution (assess of small focal lesions up to $0.5 \mathrm{~mm}$ ), examination of parts near metallic hardware, in addition gives the operator the ability to compare diseased joint with the contra lateral healthy one, assessment of the exact point of tenderness/pain depending on patient directions, and further extension of the examinations to other remote part of the limb where patient was complaining from too.

\section{Conclusion:}

High resolution ultrasound is a good alternative to other radiological methods as MRI, for diagnosis tendon and joints pathology. The most important limitations lie in its limited field of view and penetration, which potentially can result in incomplete evaluation of bony and joint anatomy.

High resolution ultrasound can be used as first line of examination, and if no abnormalities could be detected by it and the patient is still complaining, complementary MRI should be done. If ultrasound findings are positive and are going with the patient clinical diagnosis, no further investigation is needed.

\section{References}

1- LAND H., GORDON S. and WATT K.: Clinical assessment of subacromial shoulder impingement-Which factors differ from the asymptomatic population? Musculoskeletal Science and Practice, 27: 49-56, 2017.

2- SMITH T.O., BACK T., TOMS A.P. and HING C.B.: Diagnostic accuracy of ultrasound for rotator cuff tears in adults: A systematic review and meta-analysis. Clin. Radiol., 66: 1036-48, 2011.

3- DILL T.: Contraindications to magnetic resonance imaging. Heart, 94 (7): 943-8, 2008.

4- NEEDELL S.D. and ZLATKIN M.B.: Comparison of fatsaturation fast spin echo versus conventional spin-echo MRI in the detection of rotator cuff pathology. Journal of magnetic resonance imaging: JMRI, 7 (4): 674-7, 2010.

5- DINNES J., LOVEMAN E., MCINTYRE L. and WAUGH $\mathrm{N}$.: The effectiveness of diagnostic tests for the assessment of shoulder pain due to soft tissue disorders: A systematic review. Health Technol. Assess., 7: iii, 1-166, 2003.

6- CHAUHAN N.S., AHLUWALIA A., SHARMA Y.P. and THAKUR L.: A Prospective Comparative Study of High Resolution Ultrasound and MRI in the Diagnosis of Rotator Cuff Tears in a Tertiary Hospital of North India. Polish Journal of Radiology, 81: 491-7, 2016.

7- MONDAL S., DUTTA S., LAHIRI D., SINHA D., SIRCAR G., MANDAL A.K., KEJRIWAL M. and GHOSH A.: Assessment of nail unit structures by ultrasound in patients with psoriatic arthritis and their correlations with disease activity indices: A case-control study. Rheumatology international, 38 (11): 2087-93, 2018.

8- BASHIR S., FIRDOSE S.R., KAMAL Y., KHAN H.A., ARORA M., GUL S. and HASSAN N.: Correlation between high resolution ultrasonography and MRI in rotator cuff tear diagnosis. Int. J. Health Sci. Res., 4 (4): 10312, 2014.

9- BRUYN G.A., PINEDA C., HERNANDEZ-DIAZ C., VENTURA-RIOS L., MOYA C., GARRIDO J., GROEN H., PENA A., ESPINOSA R., MÖLLER I. and FILIPPUCCI E.: Validity of ultrasonography and measures of 
adult shoulder function and reliability of ultrasonography in detecting shoulder synovitis in patients with rheumatoid arthritis using magnetic resonance imaging as a gold standard. Arthritis care \& research, 62 (8): 1079-86, 2010.

10- SANVERDI E., BERKER M. and Y1LD1R1M S.A.: The importance of sphenoidal sinus pneumatization in the endoscopic transsphenoidal surgery planning; evaluation in a series of 628 patients. European Congress of Radiology, 2013.

11- BRUYN G.A., NAREDO E., MÖLLER I., MORAGUES C., GARRIDO J., De BOCK G.H., D'AGOSTINO M.A., FILIPPUCCI E., IAGNOCCO A., BACKHAUS M. and SWEN W.A.: Reliability of ultrasonography in detecting shoulder disease in patients with rheumatoid arthritis. Annals of the Rheumatic Diseases, 68 (3): 357-61, 2009.

12- De JESUS J.O., PARKER L., FRANGOS A.J. and
NAZARIAN L.N.: Accuracy of MRI, MR arthrography, and ultrasound in the diagnosis of rotator cuff tears: A meta-analysis. American Journal of Roentgenology, 192 (6): 1701-7, 2009.

13- LEVINE G.M., SILVERSTEIN M.J., RAYHANABAD J.A., WENG-GRUMLEY J.G., JI L., HOLMES D.R., SPOSTO R. and SENER S.F.: Accuracy of predicting axillary lymph node positivity by physical examination, mammography, ultrasonography, and magnetic resonance imaging. Annals of Surgical Oncology, 19 (6): 1825-30, 2012.

14- ROY J.S., BRAEN C., LEBLOND J., DESMEULES F., DIONNE C.E. and MacDERMID J.C.: Diagnostic accuracy of ultrasonography, MRI and MR arthrography in the characterisation of rotator cuff disorders: A systematic review and meta-analysis. British Journal of Sports Medicine, 49 (20): 1316-28, 2015.

\section{دراسة التصوير بالموجات الفوق صوتية لآنواع التمزقات فى العضلة المحيطة بمفصل الكتف الناتج عن الصدومات التهزيت}

المقدمة: يعد آلم الكتف هو السبب الثالث الآكثر شيوعاً لآلام المفاصل بعد آلام آسفل الظهر وآلم الركبة إصابة الكفة المدوة هي السبب

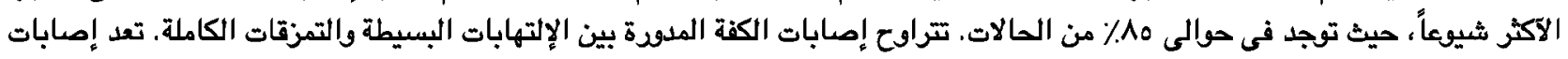

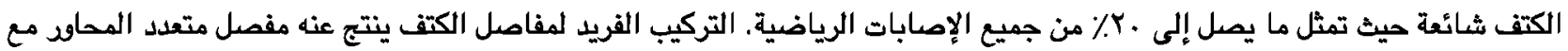

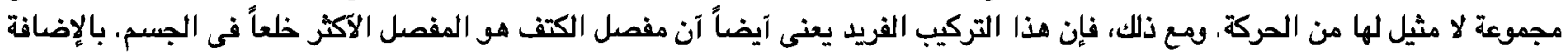

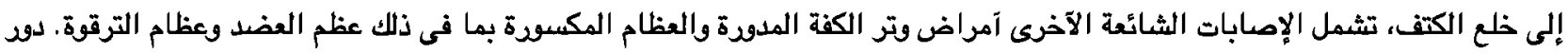

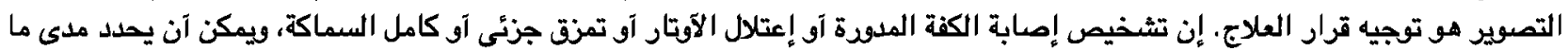

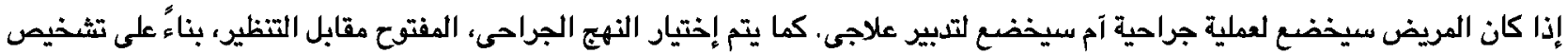
التصوير.

يستخدم التصوير بالرنين المغناطيسى الآن على نطاق واسع ويعتبر تقنية موثوقة لتقييم الآسباب المختلة لآلم الكتف مع مزايا توفير تفاصيل

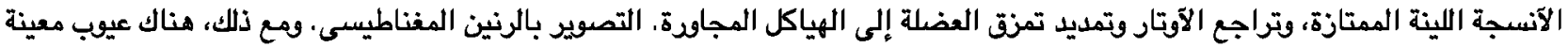

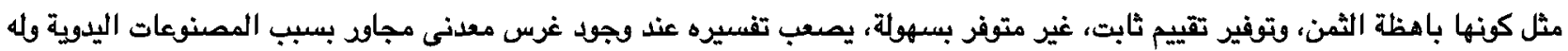

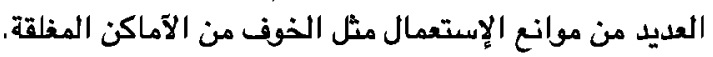

يمكن إعتبار التصوير بالموجات فوق الصوتية عالية الدقة كطرائق أولية فعالة للتصوير لمعظم آمراض الكتف لتسريع تشخيص المرضى.

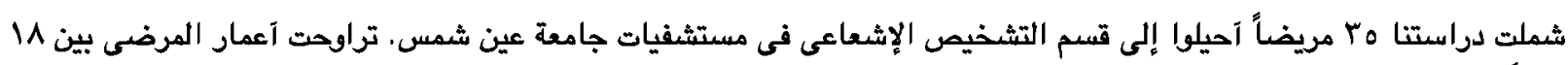

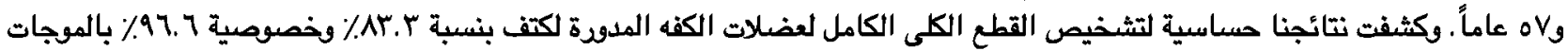

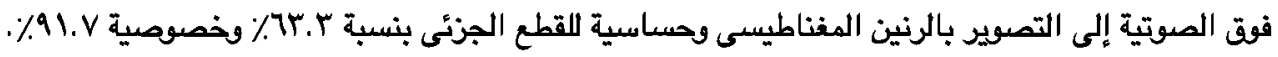

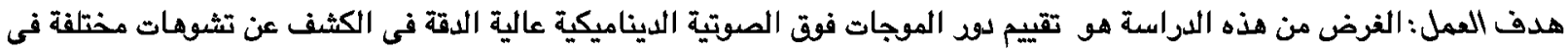

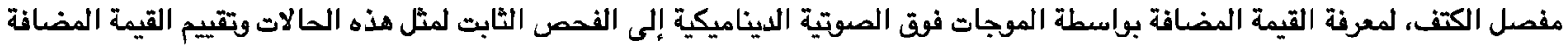

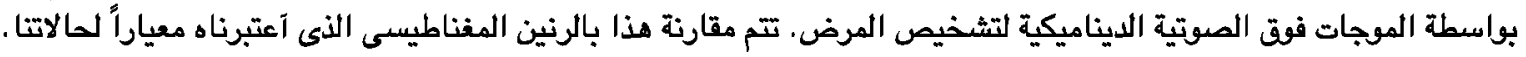

